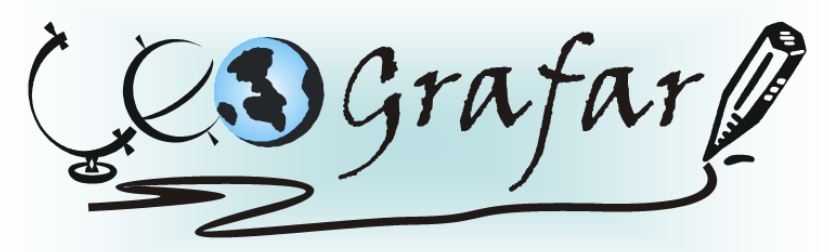

Revista Eletrônica do Programa de Pós-Graduação em Geografia - UFPR

\title{
USO DE GEOTECNOLOGIAS EM LAUDOS PERICIAIS AMBIENTAIS: ESTUDO DE CASO NO MUNICÍPIO DE JACUNDÁ, PARÁ
}

\author{
NICOLA SAVERIO HOLANDA TANCREDI ${ }^{1}$ \\ JOSIMAR RIBEIRO DE ALMEIDA ${ }^{2}$ \\ GUSTAVO AVEIRO LINS ${ }^{3}$ \\ ANTONIO JOSE TEIXEIRA GUERRA ${ }^{4}$ \\ MARIA DO CARMO OLIVEIRA JORGE ${ }^{5}$
}

\begin{abstract}
RESUMO
A perícia ambiental tem como objeto de estudo o meio ambiente, nos seus aspectos abióticos, bióticos e socioeconômicos, abrangendo a natureza e as atividades humanas, e é um meio de prova utilizado em processos judiciais que irá atender a demandas específicas advindas das questões ambientais, onde o principal objeto é o dano ambiental ocorrido, ou risco de sua ocorrência. O desenvolvimento e aplicação de ferramentas adequadas à perícia ambiental têm sido alvo de inúmeros estudos e pesquisas, com destaque para a aplicação das geotecnologias, num estágio avançado de desenvolvimento, permitindo grande acessibilidade de recursos tecnológicos a custos relativamente baixos. Neste trabalho são utilizadas ferramentas de geotecnologia na produção de informações do município de Jacundá (sudeste paraense), aqui considerado como uma grande propriedade, como peça elucidativa para instrução de um laudo pericial ambiental. Os produtos fornecidos sobre o município de Jacundá a partir da utilização de geotecnologias são representados através de mapas temáticos de declividade, altimetria, curvas de nível e uso e

\footnotetext{
${ }^{1}$ Assessor Técnico do Sistema de Proteção da Amazônia - Centro Regional de Belém (SIPAM/CR-BE). Mestre em Geociências. E-mail: nsht@ig.com.br

${ }^{2}$ Departamento de Recursos Hídricos e Meio Ambiente DRHIMA/POLI/UFRJ. E-mail: almeida@poli.ufri.br

${ }^{3}$ Companhia estadual de água e esgoto (CEDAE), Centro de Educação Superior a Distância do Estado do Rio de Janeiro CEDERJ, professor da SEE/Rio de Janeiro. E-mail: gu.lins@terra.com.br

4 Departamento de Geografia da UFRJ e Coordenador do LAGESOLOS. E-mail: antoniotguerra@gmail.com

${ }^{5}$ Pesquisadora Associada do LAGESOLOS.
} 
ocupação do solo. A área efetivamente coberta por floresta ocupa pouco mais de $20 \%$ da propriedade, caracterizando uma total inversão de valores, e conforme está previsto na legislação ambiental vigente devem ser preservados $80 \%$ da área e desmatados apenas $20 \%$ nas propriedades situadas dentro da Amazônia Legal. O município de Jacundá pode ser um retrato da situação de muitas propriedades rurais situadas na Amazônia Brasileira, em especial na região sudeste do Pará, evidenciando o colossal desafio da regularização fundiária e ambiental na região. A utilização de geotecnologias por si só não possibilita elucidar todos os aspectos inerentes à atividade da perícia ambiental, entretanto, trata-se de uma ferramenta imprescindível para a constituição de meios de prova que venham a ser utilizadas na confecção de um laudo pericial ambiental.

Palavras-chave: Geotecnologias, Laudos Periciais Ambientais, Jacundá.

\title{
USE OF GEOTECHNOLOGIES IN ENVIRONMENTAL ASSESSMENT REPORT: STUDY OF CASE IN THE MUNICIPAL DISTRICT OF JACUNDÁ, PARÁ
}

\begin{abstract}
The environmental assessment report surveys the environment, in its non-biotic, biotic and economic and social aspects, including the nature and the human activities, and is a means of evidence used in legal proceedings that will suit specific demands coming from the environmental issues, where the main object is the environmental damage occurred, or risk of its occurrence. Right tools development and application to the environmental assessment has been the target of many studies and researches, outlining the application of the geotechnologies, in an advanced degree development, allowing great accessibility of technological resources, relatively with low costs. In this study is used the geotechnological applications in the production of information of Jacundá (Southeast of Pará State), considered here as a great property, as an elucidative part for the instruction of an environmental assessment report. The products provided over the city of Jacundá from the use of geotechnologies are represented by thematic maps of slope, altimetry, contour lines and land use. The covered area by forest occupies just over $20 \%$ of the property, representing a fully inversion of values, and as is foreseen in the environmental regulations must be preserved $80 \%$ of the area and deforested only $20 \%$ in properties placed in the Legal Amazon. Jacundá can be a case of the situation of many rural properties located in the Brazilian Amazon, especially in southeast of Pará, demonstrating the colossal challenge of environmental and land regularization in the region. Alone, the use of geotechnologies doesn't elucidate all the inherent aspects involved on an environmental assessment, however, is an essential tool for the establishment of evidence that may be used to do an environmental assessment report.
\end{abstract}

Keywords: Geotechnologies, Environmental Assessment Report, Jacundá Municipality. 


\section{INTRODUÇÃO}

O desenvolvimento e aplicação de ferramentas adequadas à perícia ambiental tem sido alvo de inúmeros estudos e pesquisas, com destaque para a aplicação das geotecnologias, num estágio avançado de desenvolvimento, permitindo grande acessibilidade de recursos tecnológicos a custos relativamente baixos.

O avanço tecnológico dos últimos anos das geotecnologias, sua importância na construção do desenvolvimento sustentável, conforme foi enfatizado na Agenda 21, documento elaborado durante a Conferência das Nações Unidas para 0 Desenvolvimento, realizada no Rio de Janeiro, em 1992, e a aparente disseminação da importância da preservação ambiental, sobretudo na Amazônia, decorrem de preocupações com a qualidade de vida no mundo, e a necessidade de preservação do ar, da água e do solo, assim como da floresta e da biodiversidade.

Os Sistemas de Informações Geográficas ${ }^{6}$ (SIG) têm um papel importante na gestão das informações espaciais do meio ambiente, por facilitarem o gerenciamento por meio digital das informações cartográficas e permitirem a elaboração de diagnósticos e prognósticos decorrente dos problemas ambientais, subsidiando a tomada de decisões. Já o Sensoriamento Remoto $^{7}$ (SR), devido à rapidez e à periodicidade na captação de informações sobre a superfície terrestre, constitui-se em uma das formas mais eficazes de monitoramento ambiental, em escalas locais e regionais.

\footnotetext{
${ }^{6}$ Refere-se àqueles sistemas que efetuam tratamento computacional de dados geográficos. Um SIG armazena a geometria e os atributos dos dados que estão georreferenciados, isto é, localizados na superfície terrestre e numa projeção cartográfica qualquer. Segundo Aronoff ${ }^{3.1}$ (1989, apud Assad et al, 1998), SIG é um conjunto manual ou computacional para armazenar e manipular dados georreferenciados.

3.1 ARONOFF, S. Geographic information systems:a management perspective. Ottawa: WDI Publications, 1989.

7 Pode ser definido como a aplicação de dispositivos que, colocados em aeronaves ou satélites, nos permitem obter informações sobre objetos ou fenômenos na superfície da Terra, sem contato físico com eles. A evolução do Sensoriamento Remoto através de sensores mais potentes, proporcionando imagens cada vez melhores, associadas com as técnicas de extração de informação oriundas do processamento de imagens, ampliou sua aplicabilidade a diversas áreas do conhecimento: levantamento de recursos ambientais, análise ambiental, geologia, florestas, estudos urbanos, são algumas das áreas diretamente afetadas (ROCHA, 2002).
} 
O Pará possui um dos maiores potenciais madeireiros do Brasil e é um dos estados com maior grau de exploração, principalmente no sudeste paraense, ao longo das rodovias federal BR-010 (Belém-Brasília) e estadual PA-150. Em virtude destas características, a área de estudo é o município de Jacundá, situado no sudeste paraense, na porção oriental da Amazônia às margens da rodovia estadual PA-150, cujo território encontra-se bastante alterado, em decorrência da elevada pressão sobre os recursos do meio ambiente, especialmente, os florestais.

Áreas degradadas ou incorretamente aproveitadas segundo suas funções ambientais constituem passivos ambientais, pois são externalidades não incorporadas na avaliação dos impactos cumulativos das atividades sobre o meio ambiente. Se por um lado é difícil valorar os prejuízos causados ao meio ambiente, por outro, é necessário valorizar os proprietários de imóveis rurais que se adequam a legislação ambiental vigente.

A geração de lucros ocorre pela apropriação dos bens ambientais (tais como a água, os minérios, as florestas etc.), que servem de matéria prima para o mercado. Quando os custos de recuperação e conservação desses bens não são computados no valor de mercado dos produtos finais ou na própria cadeia de produção, o ônus do passivo gerado é suportado por toda a coletividade.

Neste trabalho são utilizadas ferramentas de geotecnologias para tratamento dos dados geoambientais (bases cartográficas digitais, imagem CBERS e o modelo digital de elevação), através do programa ArcGIS 9.0 e seus recursos, como as extensões Xtools Pro 3.0 e Spatial Analyst, na produção de informações do município de Jacundá, considerado aqui como uma grande propriedade, como peça elucidativa para instrução de um laudo pericial ambiental.

\section{REVISÃO TEÓRICA}

Saroldi (2009, p. 93) destaca que o Princípio 15 da Declaração do Rio de Janeiro sobre o Meio Ambiente e Desenvolvimento (1992) faz referência à ampla observância pelos Estados do princípio da precaução de modo a proteger o meio ambiente de 
acordo com suas capacidades. Quando houver ameaça de danos sérios ou irreversíveis, a ausência de absoluta certeza científica não deve ser utilizada para postergar medidas eficazes e economicamente viáveis para prevenir a degradação ambiental.

Quando o valor social dos benefícios dos quais decorre a atividade é inferior aos custos e danos ambientais, ocorre um desequilíbrio devido ao uso não pago dos bens ambientais. Esse conceito é definido economicamente como uma externalidade, posto que reflete um custo que não foi levado em consideração, e ocorre devido a falhas de mercado e de governo (ALBUQUERQUE, 2011). Assim, quando a propriedade possui passivos ambientais, esta sofre uma redução econômica no valor do bem (BENATTI, 2005, p. 220). Essa redução se dá em virtude dos custos necessários para promover a recomposição dos danos ambientais ocorridos na propriedade.

Todo proprietário rural tem de averbar no Cartório de Registro de Imóveis onde está registrada a propriedade, a Reserva Legal que corresponde, no mínimo, a 80\% da propriedade em áreas situadas na Amazônia Legal (SEDRIM, 2004, p. 14-15). A localização e demarcação da Reserva Legal são realizadas pelo órgão Estadual de Meio Ambiente.

Além da averbação da reserva legal, o proprietário rural deve manter preservadas ou recompor as Áreas de Preservação Permanente, que são definidas pelo inciso II, Parágrafo $2^{\circ}$, do Artigo $1^{\circ}$ do Código Florestal Brasileiro (BRASIL, 1965) como "área coberta ou não por vegetação nativa, com a função ambiental de preservar os recursos hídricos, a paisagem, a estabilidade geológica, a biodiversidade, o fluxo gênico de fauna e flora, proteger o solo e assegurar o bem-estar das populações humanas".

As contravenções ambientais são punidas através da Lei de Crimes Ambientais (Lei n. ${ }^{\circ} 9.605$ de 12/02/98), como os artigos 38 e 39 que atuam nas infrações contra a flora (BRASIL, 1998).

O artigo 38 determina que "Destruir ou danificar floresta considerada de preservação permanente, mesmo que em formação, ou utilizá-la com infringência das normas de proteção: Pena - detenção, de um a três anos, ou multa, ou ambas as penas cumulativamente. Parágrafo único - Se o crime for culposo, a pena será reduzida à 
metade". Enquanto o artigo 39 afirma que "Cortar árvores em floresta considerada de preservação permanente, sem permissão da autoridade competente: Pena - detenção, de um a três anos, ou multa, ou ambas as penas cumulativamente".

O decreto n. ${ }^{\circ}$ 6.514, de 22/07/2008, que regulamenta a Lei de Crimes Ambientais (LCA), dispõe sobre a especificação das sanções aplicáveis às condutas e atividades lesivas ao meio ambiente, e dá outras providências. Os artigos 43 e 44 deste Decreto regulamentam os artigos 38 e 39 da LCA (BRASIL, 2008). Segundo o artigo 43 "Destruir ou danificar florestas ou demais formas de vegetação natural ou utilizá-las com infringência das normas de proteção em área considerada de preservação permanente, sem autorização do órgão competente, quando exigível, ou em desacordo com a obtida: Multa de $\mathrm{R} \$ 5.000,00$ (cinco mil reais) a $\mathrm{R} \$ 50.000,00$ (cinqüenta mil reais), por hectare ou fração". De acordo com o artigo 44 "Cortar árvores em área considerada de preservação permanente ou cuja espécie seja especialmente protegida, sem permissão da autoridade competente: Multa de $R \$ 5.000,00$ (cinco mil reais) a $R \$$ $20.000,00$ (vinte mil reais) por hectare ou fração, ou $R \$ 500,00$ (quinhentos reais) por árvore, metro cúbico ou fração".

Segundo Almeida (2000, p. 41), laudo é o resultado da perícia em conclusões escritas e fundamentadas, onde serão apontados os fatos, circunstâncias, princípios e parecer sobre a matéria submetida a exame do especialista, adotando-se respostas objetivas aos quesitos.

A legislação não prescreve a forma com que os laudos devam ser apresentados. No entanto, o laudo deve ter requisitos extrínsecos: forma escrita e subscrita pelo autor (es); e intrínsecas, ser completo, claro, circunscrito ao objeto da perícia e fundamentado.

Um laudo completo deve conter três fases. A primeira fase, geralmente denominado "histórico", consiste na síntese das alegações e posições conflitantes das partes. Segue-se a ela uma coisa expositiva, de modo a restaurar a coisa sujeita a exame, com todos os dados pertinentes, as operações realizadas, fatos e circunstâncias ocorridos no curso das diligências. A última fase deverá ser conclusiva (parecer), apresentando as respostas às indagações. O laudo pode ser instruído com 
documentos, plantas, croquis, fotografias, pesquisas ou quaisquer outras peças elucidativas e/ou complementares.

A perícia ambiental possui como objeto de estudo o meio ambiente, nos seus aspectos abióticos, bióticos e socioeconômicos, abrangendo a natureza e as atividades humanas. Segundo a Lei oㅜ 9.605/98 (lei dos crimes ambientais), o crime ambiental pode ocorrer, contra a fauna, a flora, a administração ambiental, o ordenamento urbano e o patrimônio cultural, por ação de poluentes, ou outros casos específicos, configurando dessa forma, uma vasta gama de objetos de estudo (ALMEIDA, 2006, p. 43).

Segundo Correia (2003, p. 4), a perícia ambiental é um meio de prova utilizado em processos judiciais, sujeito à mesma regulamentação prevista pelo Código do Processo Civil (CPC), com a mesma prática forense, mas que irá atender a demandas específicas advindas das questões ambientais, onde o principal objeto é o dano ambiental ocorrido, ou risco de sua ocorrência.

A complexidade da realização de perícia ambiental é confirmada pelos resultados apresentados por Araújo8 (2004 apud SAROLDI, 2009, p. 111) referentes às ações instauradas pela Promotoria de Justiça de Proteção ao Meio Ambiente da Capital (Rio de Janeiro - RJ), no período de outubro de 1986 a abril de 2003, que indicaram que somente em menos de $10 \%$ destas ações haviam sido proferidas sentenças decorrentes da realização de perícia.

A perícia ambiental, assim como as outras modalidades de perícia, deve ser realizada por técnico de comprovada idoneidade profissional e possuidor de conhecimentos técnico-científicos especializados para verificação da complexidade da verdade dos fatos denunciados (SAROLDI, 2009, p. 110).

Não se pode perder de vista que uma perícia, na temática ambiental ou não, tem objetivo preciso, qual seja, produzir prova de determinado fato. A perícia é, neste sentido, um meio de prova. Também não se pode desconsiderar o caráter científico que a prova pericial requer. Toda e qualquer perícia deve estar calcada no conhecimento científico e, por conseguinte, deve ser executada a partir de método científico

\footnotetext{
${ }^{8}$ ARAÚJO, Lilian Alves de. Ação Civil Pública. 2 Edição. Rio de Janeiro: Lumen júris, Ed., 2004.
} 
consagrado e aceito pelos profissionais especialistas na matéria objeto da perícia. Se a perícia não tiver embasada no conhecimento e método científicos adequados, ou então, se o profissional incorrer em imperícia, imprudência ou negligência, o mesmo poderá sofrer sanções administrativas, civis, e até mesmo criminais, conforme o caso (CERRI, 2011).

\section{METODOLOGIA}

A definição da área de estudo considerou como critério a localização da sede do município de Jacundá, que apresenta grande impacto de exploração sobre os recursos naturais. Realizou-se pesquisa bibliográfica, com análise de dados e informações técnicas a respeito do assunto e da aplicação do software de geoprocessamento, ArcGIS 9.0.

O desenvolvimento do trabalho na confecção da classificação de uso e ocupação do solo foi baseado em classificadores não supervisionados, pelo qual analisou-se o território do município de Jacundá, aplicando técnicas de sensoriamento remoto, onde identificou-se as formas de utilização da área, que foram definidas como: água, área desmatada, área urbana, floresta, floresta explorada, nuvem e sombra de nuvem. Nesta abordagem, utilizou-se cena de satélite $\mathrm{CBERS}^{9}$ georreferenciada, referente ao mês de julho de 2006, como base de informações; que foram adquiridas gratuitamente no site do Instituto de Pesquisas Espaciais (INPE, 2006).

Durante a classificação de dados digitais, os alvos do universo real recebem a denominação genérica de classes ou classes temáticas. Na classificação, procura-se rotular cada pixel ${ }^{10}$ da imagem segundo a ocupação do solo, semelhante ao que se faz

\footnotetext{
${ }^{9}$ O Programa CBERS resulta de uma cooperação assinada em 6 de julho de 1988 entre a China e o Brasil para desenvolver dois satélites de observação da Terra. Esse programa conjunto de Satélites Sino-Brasileiros de Recursos Terrestres (CBERS) combina os recursos financeiros e de especialistas dos dois países para estabelecer um sistema completo de sensoriamento remoto, que é competitivo e compatível com o presente cenário internacional. $\mathrm{O}$ programa CBERS foi concebido como modelo de cooperação horizontal e intercâmbio entre países em desenvolvimento.

${ }^{10}$ Tratam-se de elementos da imagem que são armazenados como matrizes, possuindo um valor proporcional à energia eletromagnética refletida ou emitida pela área da superfície terrestre (SANTOS, 2002).
} 
na abordagem visual. Para isso, utilizam-se programas apropriados, também denominados algoritmos de classificadores ou simplesmente classificadores. A categorização (rotulação) dos valores dos níveis de cinza é feita utilizando algoritmos estatísticos (programas computacionais) de reconhecimento de padrões espectrais. Dependendo do algoritmo utilizado neste procedimento, a classificação é dita supervisionada ou não supervisionada.

Tanto a classificação supervisionada quanto a não-supervisionada possuem regras de decisão para que o classificador associe determinados pixel a determinada classe ou regiões de similaridade de níveis de cinza. Tais regiões são baseadas nas características espectrais do pixel, ou do pixel e seus vizinhos (MOREIRA, 2005, p. 284).

Ainda segundo Moreira (2005, p. 291-292), o uso de classificadores nãosupervisionados objetiva eliminar a subjetividade no processo de obtenção das amostras, para criar o pacote de treinamento, onde certos algoritmos necessitam de alguns parâmetros que devem ser fornecidos ao sistema, tais como no classificador $\mathrm{K}$ Médias $^{11}$ : a) número de classes espectrais prováveis dentro da área de estudo; b) distância mínima desejada entre os valores dos níveis digitais de duas classes; e c) número de interações realizadas, ou seja, quantas vezes o classificador deve repetir a operação de análise do pixel em relação aos atributos das classes contidas na área. A partir desses parâmetros, o sistema realiza o agrupamento (clustering) dos pixels homogêneos em $n$ classes espectrais. Quase todos os classificadores nãosupervisionados têm como regra de decisão a distância mínima entre o valor do nível digital do pixel e o valor médio dos números digitais das classes espectrais contidas na área de estudo.

$\mathrm{Na}$ classificação não-supervisionada, quanto maior a heterogeneidade das amostras, maior a certeza de que todas as classes possíveis estão representadas (SANTOS, 2002, p. 19).

\footnotetext{
${ }^{11}$ Calcula inicialmente as classes distribuindo em uma classe uniformemente no espaço e então aglomera classe por classe em um processo interativo usando a técnica de distância mínima. Melhor será a classificação quanto melhor for agrupada a nuvem de pixels (SULSOFT, 2006).
} 
O procedimento para a classificação utilizou a extensão spatial analyst ${ }^{12}$ do programa ArcGIS 9.0, onde executou-se a função reclassify.

Em seguida, selecionou- se a imagem de entrada para classificação, que foi a cena de satélite CBERS 161/105, com data de aquisição em 04.07.2006, determinandose o número de classes a serem criadas e o método de classificação a ser utilizado, que foi o "Natural Breaks (Jenks)", e, finalmente o nome de saída para o arquivo de classificação gerado.

Após a classificação, efetuou-se a edição manual no próprio ambiente do programa ArcGIS 9.0, visando corrigir algumas áreas que apresentavam classificações incorretas, de tal forma a gerar um produto que representasse com máxima fidelidade 0 uso do solo no município de Jacundá. Em seguida, utilizando-se a extensão Xtools Pro 3.0, quantificou-se as áreas em hectares.

Os mapas altimétricos, de curvas de nível e de declividade foram produzidos pela utilização da imagem de radar SRTM (Shuttle Radar Topography Mission), disponível em SRTM (2006), também no ambiente do programa ArcGIS 9.0, utilizando a extensão spatial analyst.

Por fim, efetuaram-se avaliação e discussão dos resultados obtidos sobre sua utilização como subsídios à tomada de decisões em laudos periciais ambientais, elaborando mapas temáticos para melhor visualização dos resultados.

\section{RESULTADOS E DISCUSSÕES}

Os produtos fornecidos sobre o município de Jacundá a partir da utilização de geotecnologias são representados através de mapas temáticos, que podem instruir de forma complementar ou elucidativa um laudo pericial ambiental.

A análise dos resultados apresentados permite inferir que a área do município de Jacundá recoberta com água é bastante extensa, em virtude de mais de $14 \%$ da sua propriedade estar inserida no Lago de Tucuruí, formado pelo barramento do rio Tocantins para construção da Hidrelétrica de Tucuruí, a maior genuinamente brasileira.

\footnotetext{
${ }^{12}$ Analista Espacial.
} 
O município de Jacundá possui área aproximada de 200.600 hectares, ou seja, $2.006 \mathrm{~km}^{2}$. O gráfico da Figura 1 mostra que, pelo menos $60,35 \%$ da sua área encontrase desmatada, caracterizando total desrespeito à legislação ambiental, gerando um passivo ambiental elevadíssimo pelo mau uso dos recursos naturais. O desmatamento neste município está em estágio tão avançado que muitas áreas de preservação permanente estão sendo degradadas, inclusive aquelas situadas às margens do lago de Tucuruí, infringindo gravemente o artigo $2^{\circ}$ do Código Florestal Brasileiro que versa sobre áreas de preservação permanente, ao redor de reservatórios naturais ou artificiais.

Detectou-se pouco mais de 3.000 hectares de florestas com indícios de exploração seletiva de madeira, representando cerca de $1,6 \%$ do município de Jacundá. Este índice deve ser considerado elevado, em virtude do elevado grau de exploração já existente na área. Esta classe de uso apresenta como característica a predominância de tonalidades verdes, com ocorrências de agrupamento de pixels rosa, que representam pátios de estocagem de madeira serrada.

Cerca de $2 \%$ de Jacundá foram impossibilitados de classificação em virtude de estarem recobertos por nuvem e/ou sombra de nuvem, representando mais de 4.000 hectares. A presença de nuvens durante o processo imageamento consiste em uma das limitações dos sensores óticos, como a imagem de satélite CBERS.

A área efetivamente coberta por floresta ocupa pouco mais de $20 \%$ do município, caracterizando uma total inversão de valores, e conforme está previsto na legislação ambiental vigente devem ser preservados $80 \%$ da área e destinados a uso alternativo dos solos apenas $20 \%$ nas propriedades situadas dentro da Amazônia Legal. 
Figura 1 - Uso do solo no município de Jacundá

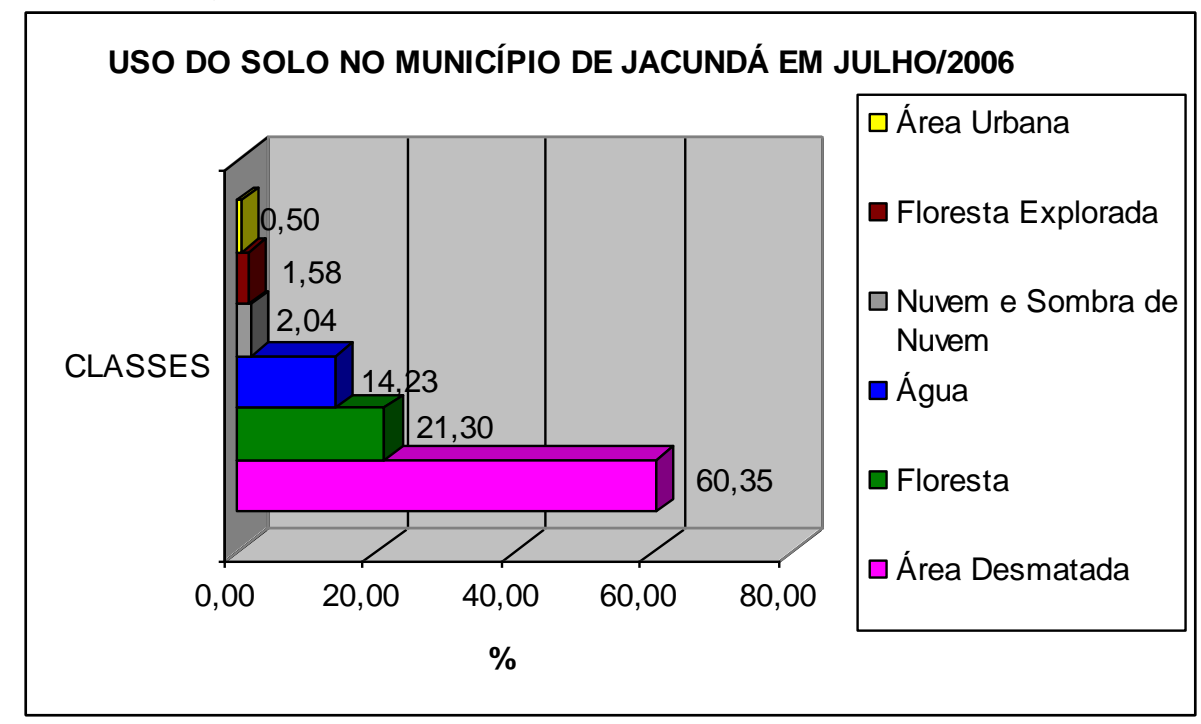

Fonte: TANCREDI, 2007.

O mapa de uso do solo é referente à imagem de satélite CBERS 161/105, de 04 de julho de 2006, com destaque para a quantificação de uso e ocupação do solo das classes levantadas (Figura 2).

A utilização da imagem de radar SRTM possibilitou a geração dos mapas altimétrico (Figura 3), e de curvas de nível (Figura 4) da extensão territorial de Jacundá.

Em toda a extensão territorial do município existe relevo suave, sendo a cota mais alta com 322 metros e a menor com apenas 31 metros acima do nível do mar, representando um desnível de 291 metros, conforme é apresentado no mapa apresentado na Figura 4, extraído da imagem de radar SRTM (Shuttle Radar Topography Mission). Conseqüentemente, existe pouca declividade na área de estudo, sendo as mais íngremes, possuindo pouco mais de $22^{\circ}$ de inclinação.

O mapa de declividade (Figura 5) apresenta cinco classes, sendo a primeira com valores que variam de 0 a $3^{\circ}$ (relevo bem plano), a segunda com valores entre 3 e $5^{\circ}$ (relevo plano a suavemente ondulado), a terceira com valores entre 5 e $10^{\circ}$ (relevo suave ondulado a ondulado), a quarta com declividade entre 10 e $17^{\circ}$ (relevo ondulado a fortemente ondulado) e finalmente a quinta contém valores de declividade entre $17 \mathrm{e}$ a máxima declividade encontrada no município, que é de $22^{\circ}$ (relevo fortemente 
ondulado a montanhoso), a partir da imagem de radar SRTM utilizada (DE BIASE, 1993 MODIFICADO).

As informações apresentadas estão georreferenciadas, ou seja, desde que o perito esteja munido com um GPS (Global Position System), será possível definir sua localização espacial a partir dos mapas elaborados, bem como previamente levantar pontos de interesse a serem vistoriados durante as atividades de campo, que são obrigatórias para a validação dos dados.

Figura 2 - Mapa de Classificação de Uso e Ocupação do Solo

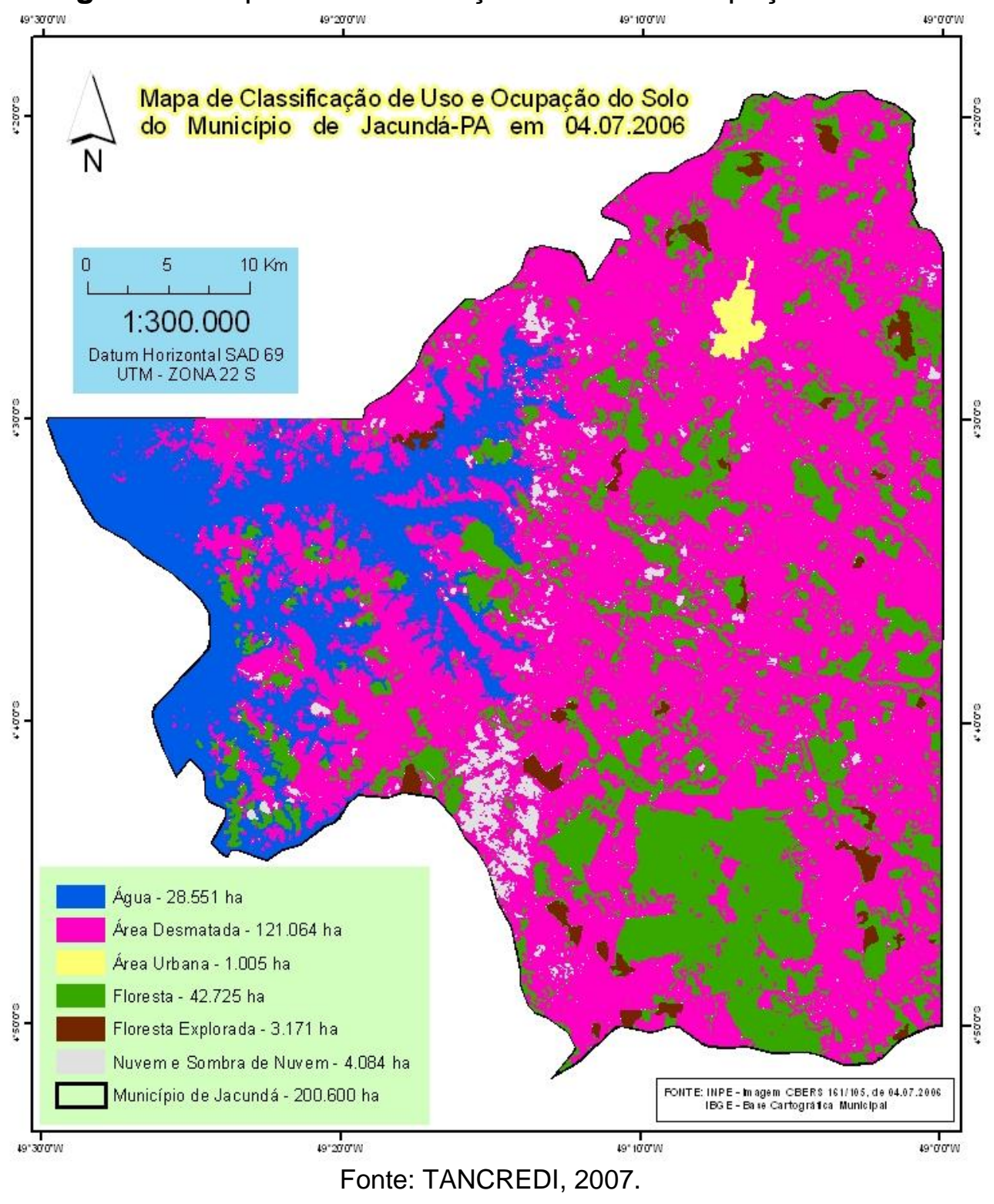


Figura 3 - Mapa Altimétrico do Município de Jacundá

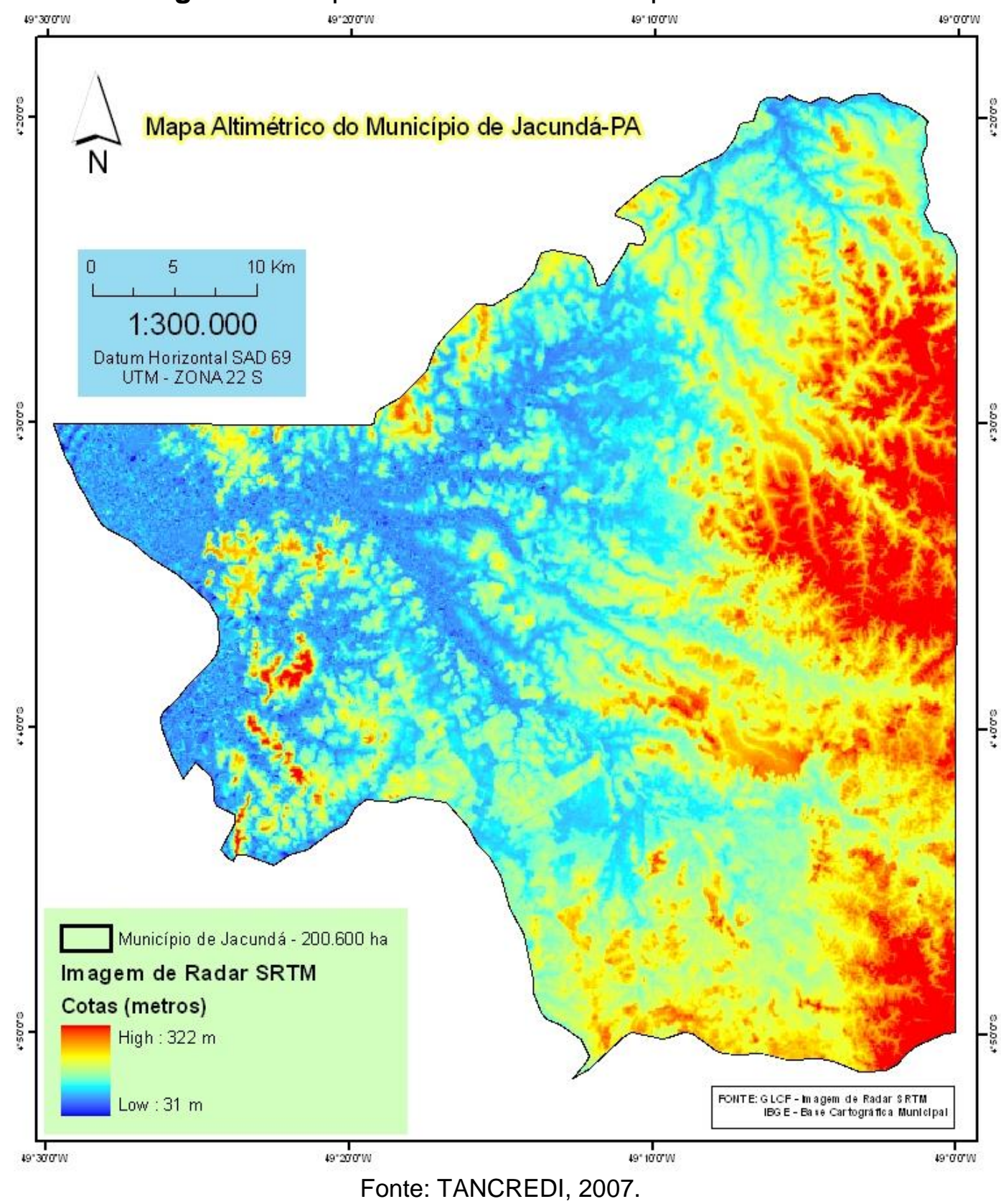


Figura 4 - Mapa de Curvas de Nível do Município de Jacundá

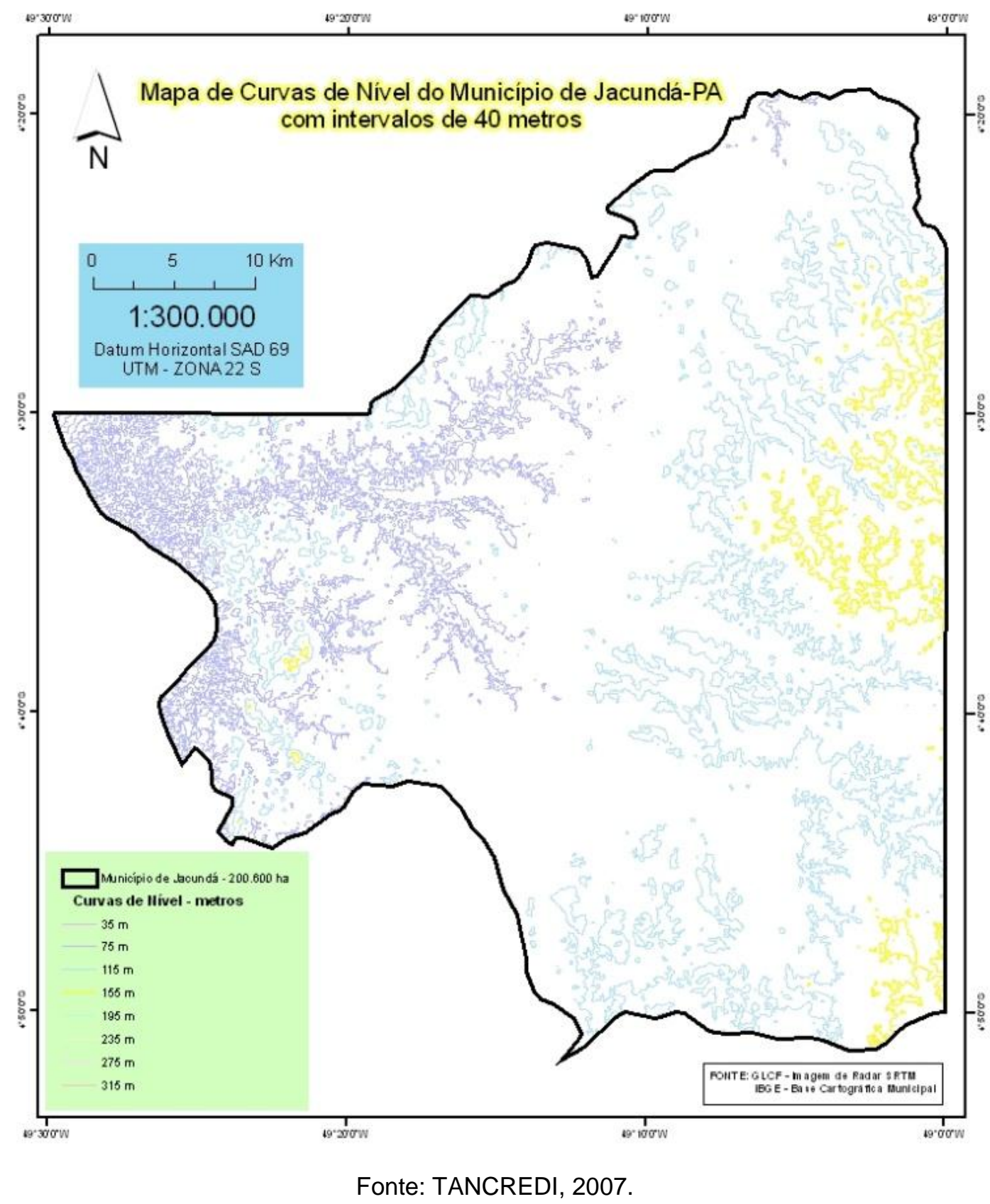


Figura 5 - Mapa de Declividade do Município de Jacundá

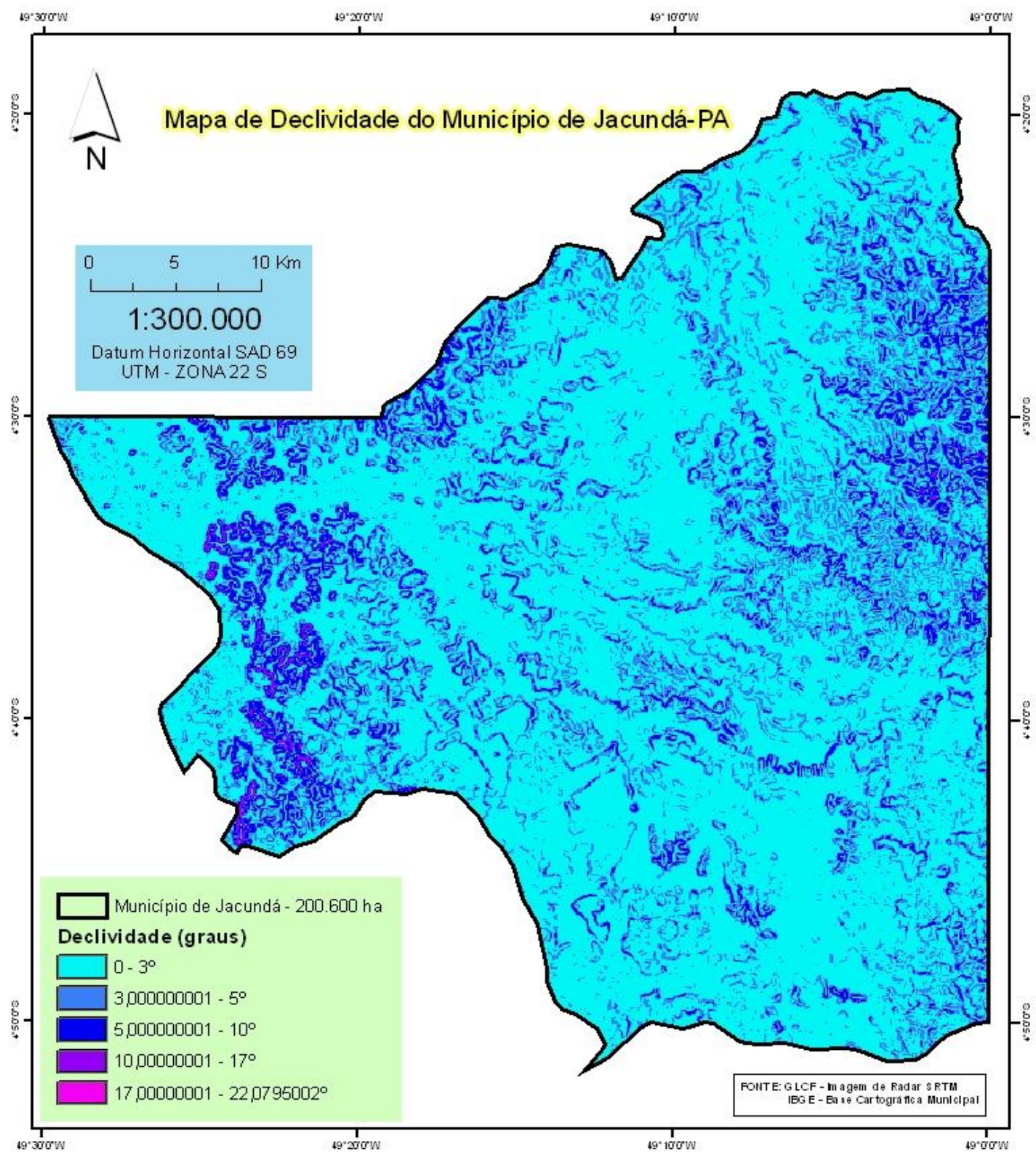

Fonte: TANCREDI, 2007. 


\section{CONCLUSÕES}

A utilização de geotecnologias, por si só, não possibilita elucidar todos os fatores inerentes à atividade da perícia ambiental, entretanto, trata-se de uma ferramenta imprescindível para a constituição de meios de prova que venham a ser utilizados na confecção de um laudo pericial ambiental.

Os mapas apresentados possibilitam ao perito uma familiarização mais rápida com a área a ser estudada, além de fornecerem informações valiosíssimas sobre vários aspectos, tais como: uso do solo, altimetria, curvas de nível e declividade, dispondo de dados que podem nortear seu trabalho de avaliação do funcionamento da paisagem, quantidade e qualidade de biomassa disponível, condições climáticas, características do terreno e pressão antrópica, entre outros, com informações geradas a partir de uma metodologia cientificamente adequada.

O município de Jacundá, considerado neste trabalho como uma grande propriedade é um retrato da situação de muitas propriedades rurais situadas na Amazônia Brasileira, em especial na região Sudeste do Pará, que super exploram seus recursos naturais e estão à margem da legislação ambiental, evidenciando o colossal desafio da regularização ambiental na região.

O uso de geotecnologias permite mensurar cientificamente o passivo ambiental de uma propriedade segundo a legislação ambiental vigente, avaliando a ocorrência do dano e apurando sua real extensão, sendo fundamental para que o juiz tome sua decisão corretamente.

\section{REFERÊNCIAS}

ALBUQUERQUE, F. S. A responsabilidade civil e o princípio do poluidor pagador. Disponível em: <http://www.egov.ufsc.br/portal/sites/default/files/anexos/26349-263511-PB.html>. Acesso em: 18.12.2011.

ALMEIDA, J. R. de. Perícia ambiental. Rio de Janeiro: Thex Ed., 2000.

Perícia ambiental, judicial e securitária - Impacto, Dano e Passivo Ambiental. Rio de Janeiro: Thex Ed., 2006. 
ASSAD, E. D.; SANO, E. E. Sistema de Informações Geográficas: Aplicações na Agricultura. Brasília: Serviço de Produção de Informação - SPI, 1998.

BENATTI, J. H. Indenização da cobertura vegetal no imóvel rural: um debate sobre o papel da propriedade na contemporaneidade. In: FREITAS, V. P. de (Coord.). Direito Ambiental em Evolução. № 4. Curitiba: Juruá, 2005

BRASIL. Lei no 4.771, de 15 de setembro de 1965. Institui o novo código florestal. Diário Oficial da União, Poder Executivo, Brasília-DF, 16/09/1965.

. Constituição da República Federativa do Brasil, de 05 de outubro de 1988. Diário Oficial da União, Poder Executivo, Brasília-DF, 05/10/1988.

Lei $\mathrm{n}$ - 9.605, de 12 de fevereiro de 1998. Dispõe sobre as sanções penais e administrativas, de condutas e atividades lesivas ao meio ambiente, e dá outras providências. Diário Oficial da União, Poder Executivo, Brasília-DF, 13/02/1998.

Decreto no 6.514, de 22 de julho de 2008. Dispõe sobre as infrações e sanções administrativas ao meio ambiente, estabelece o processo administrativo federal para apuração destas infrações, e dá outras providências. Diário Oficial da União, Poder Executivo, Brasília-DF, 22/07/2008.

CERRI, L. E. da S. Laudos e Perícias Ambientais. Disponível em: <http://www.periciasambientais.com.br/lauds.pdf>. Acesso em 03.07.2011.

CORREIA, P. A. S. Perícias Ambientais. Disciplina - Teoria Ecológica e Análise Ambiental - Universidade Federal da Paraíba. Orientação: Prof. Roberto Sasi. 2003. João Pessoa - PB. 14 p.

De BIASE, M. A Carta Clinográfica: Os Métodos de Representação e sua Confecção. Revista de Geografia, São Paulo, v. 6, p. 45-60, 1993.

INPE. Instituto Nacional de Pesquisas Espaciais. Disponível em: http://www.dgi.inpe.br/. Acesso em 15.11.2006.

MOREIRA, M. A. Fundamentos do Sensoriamento Remoto e Metodologias de Aplicação. 3 ed. atual. ampl. Viçosa: UFV Ed., 2005.

ROCHA, C. H. B. Geoprocessamento: tecnologia transdisciplinar. Juiz de Fora: Autor, Ed., 2002.

SANTOS, F. A. A. dos. Processamento digital de imagem de sensoriamento remoto: noções básicas. Manaus: Agência de Cooperação Técnica, 2002.

SAROLDI, M. J. L. de A. Perícia Ambiental e suas Áreas de Atuação. Rio de Janeiro: Lumen Juris, Ed., 2009. 
SEDRIM, I.; LIMA, R. E. Dias de; SANTOS, V. H. dos. Fazenda Legal é produto tranqüilo - Roteiro para o cumprimento da Legislação da Propriedade Rural. Belém, FAEPA/SENAR, 2004.

SRTM - Shuttle Radar Topography Mission. Disponível em: <http://srtm.usgs.gov/mission.html>. Acesso em 15.12.2006.

SULSOFT. Guia do ENVI em Português. Disponível: <http://www.envi.com.br>. Acesso em 01.06.06.

TANCREDI, N. S. H. Informações geográficas do município de Jacundá. 2007. Marabá-PA.

(Recebido em 13.04.2011. Aceito em 09.12.2011) 